\title{
Supplementation of the diet of dairy cows with trehalose results in milk with low lipid peroxide and high antioxidant content
}

\author{
N. Aoki, ${ }^{* 1}$ S. Furukawa,${ }^{* 1}$ K. Sato, ${ }^{* 2}$ Y. Kurokawa, $†$ S. Kanda, ${ }^{*}$ Y. Takahashi, $\ddagger$ H. Mitsuzumi, $\S$ and H. Itabashi\# \\ *Department of Biological Production, Tokyo University of Agriculture and Technology, Tokyo, 183-8509, Japan \\ †Graduate School of Biosphere Science, Hiroshima University, Higashihiroshima, 739-0046, Japan \\ $\ddagger$ National Institute of Animal Health, Hokkaido Research Station, Hokkaido, 062-0045 Japan \\ §Hayashibara Biochemical Laboratories Inc., Okayama, 700-0907, Japan \\ \#Nippon Veterinary and Animal Science University, Tokyo, 180-8602, Japan
}

\section{ABSTRACT}

The objective of this study was to investigate the effect of dietary supplementation with the disaccharides trehalose and cellobiose on antioxidant activity in rumen fluid, blood, and milk of dairy cows. Nine Holstein dairy cows housed in a free-stall barn were divided into 3 groups, with each group receiving a different dietary treatment (a control diet, a 1\% trehalose-supplemented diet, or a $1 \%$ cellobiose-supplemented diet) following a $3 \times 3$ Latin square design. Feed intake and milk production increased in cows receiving the trehalosesupplemented diet compared with those receiving the control and cellobiose-supplemented diets. The total protozoa numbers in the rumen fluid of cows fed trehalose- or cellobiose-supplemented diets were greater than those of the control group. The C18:0 and C18:1 fatty acid content was increased in the milk of cows fed the trehalose-supplemented diet compared with that of the control group, and the C18:3n-3 fatty acid content in the milk of cows fed the cellobiose-supplemented diet was less than that of the control group. Plasma biochemical parameters were unchanged among the different treatments. In rumen fluid, 1,1-diphenyl-2-picrylhydrazyl radical scavenging activity and superoxide dismutase activity were increased $2 \mathrm{~h}$ after feeding in cows receiving the cellobiose-supplemented diet compared with the control group, and the concentration of thiobarbituric acid reactive substances in the rumen fluid of cows fed the cellobiose-supplemented diet was decreased. In contrast, the values of these parameters measured in the milk of cows fed the cellobiose-supplemented diet were no different from those of control cows. Dietary supplementation with trehalose did, however, bring about

\footnotetext{
Received December 1, 2009.

Accepted April 26, 2010.

${ }^{1}$ These authors contributed equally to this work

${ }^{2}$ Corresponding author: satokan@cc.tuat.ac.jp
}

an improvement of the oxidative status of milk and blood in these animals compared with controls. These results provide the first evidence supporting the use of dietary disaccharides to decrease lipid peroxide levels and increase the antioxidant content of dairy cow milk. The findings suggest that disaccharides, particularly trehalose, might be useful as supplements for reducing oxidative stress and improving the quality of milk for human consumption, as well as possibly impairing the processes that give rise to lipid oxidation odor in dairy cow milk.

Key words: oxidative status, trehalose, cellobiose

\section{INTRODUCTION}

Oxidative stress leads to aging and disease in animals and is caused by an imbalance between the production of reactive oxygen species (ROS) and antioxidant activity. Although ROS play an important role in biological defense against infections, they also injure cells, DNA, RNA, proteins, carbohydrates, and lipids, which can, in turn, give rise to serious health problems (Boots et al., 2008; Herrera et al., 2009). The harmful consequences of ROS activity are restricted by antioxidant metabolism and antioxidant factors. A recent trend in consumer habits has shown an increase in the intake of antioxidant nutrients, such as vitamins and polyphenols, which have a putative role in the prevention of disease and aging and in the optimization of human health (Mukhtar and Ahmad, 2000). To this extent, the availability of foods with antioxidant properties and low lipid peroxide levels forms part of this consumer demand.

A serious problem for the dairy industry is the lipid oxidation of milk fats, which gives rise to lipocatabolic odor (Lindmark-Månsson and Akesson, 2000). These odors result from unsaturated fatty acid oxidation by reactive oxygen during long-term preservation (AlMabruk et al., 2004). Based on this concept, it has 
been reported that the supplementation of antioxidative nutrients; that is, vitamin E (Al-Mabruk et al., 2004; Sympoura et al., 2009), in the diets of dairy cows could result in milk with a low lipid peroxide content and high antioxidant activity.

Trehalose is natural disaccharide composed of 2 molecules of glucose joined by an $\alpha, \alpha-1,1$ glucosidic linkage; it is used widely, particularly as a food additive and in cosmetics, as well as for its antioxidant activity (Oku et al., 2003). Because it has been reported that trehalose reduces the oxidation of unsaturated fatty acids (Oku et al., 2005), one could postulate that the supplementation of trehalose in the diet of dairy cows might decrease oxidative stress indicators and lipid peroxide content in milk. Although the effects of dietary supplementation of trehalose on antioxidant activity in ruminants have not been previously reported, the supplementation could also be reflected in an increase in the antioxidant content of rumen fluid, blood, and milk. We hypothesized that dietary trehalose might protect against oxidative stress in dairy cows, thereby resulting in milk with low lipid peroxide and high antioxidant content, with subsequent implications for milk quality and production. To this extent, we investigated whether supplementation of a dairy cow diet with trehalose protects against lipid peroxidation in the rumen fluid, blood, and milk of dairy cows and thereby improves milk quality and production efficiency. In addition to providing evidence that trehalose has specific and novel actions on antioxidant activity in dairy cows, we compared its effects to those of cellobiose, a disaccharide compound consisting of 2 glucose molecules joined by a $\beta-1,4$ glucosidic linkage, which does not exhibit antioxidative activity.

\section{MATERIALS AND METHODS}

\section{Animals and Treatments}

Nine multiparous Holstein cows (average BW of 708 $\mathrm{kg} \pm 8$, milk production of $21.1 \pm 0.5 \mathrm{~kg} / \mathrm{d}, 189 \pm 18$ DIM, and lactation number $2.8 \pm 0.2$ ) were housed in a free-stall barn. They were divided into 3 experimental groups (basal diet, 1\% trehalose-supplemented diet, and $1 \%$ cellobiose-supplemented diet, $\mathrm{n}=3$ ). Cows were fed a TMR without supplementation (control) or a TMR supplemented with $1 \%$ trehalose or $1 \%$ cellobiose (Table 1). Diet and water were provided freely. The experiments followed a $3 \times 3$ Latin square design. Each period contained an adaptation period of $11 \mathrm{~d}$ and a test period of $3 \mathrm{~d}$. Cows were milked at 0900 and $1700 \mathrm{~h}$ and fed after milking. The Animal Care and Use Committee of the Tokyo University of Agriculture and Technology approved all procedures.
Table 1. Ingredient and nutrient composition of diets

\begin{tabular}{lc}
\hline Composition & Diet (\% of DM) \\
\hline Ingredient & \\
Sudangrass hay & 14.1 \\
Corn silage & 20.9 \\
Alfalfa hay cube & 20.4 \\
Beet pulp & 3.2 \\
Wheat bran $_{\text {Soybean meal }}$ & 3.2 \\
Cottonseed $_{\text {Concentrate mixture }}{ }^{2}$ & 1.3 \\
Nutrient composition $^{2}$ & 4.0 \\
Total digestible nutrients $_{\text {CP }}$ & 33.1 \\
Ether extract & 72.9 \\
NDF & 16.2 \\
\hline
\end{tabular}

${ }^{1}$ Contained $47 \%$ grain (heat-treated corn, barley, wheat flour, milo, ray), $27 \%$ chaff and bran (rice bran, corn gluten feed, wheat bran), $22 \%$ oil seed meals (soybean meal, rapeseed meal, corn gluten meal, linseed meal), $4 \%$ others (molasses, calcium, carbonate, sodium chloride, phosphate).

${ }^{2}$ Estimated from Standard Tables of Feed Composition in Japan (Agriculture, Forestry and Fisheries Research Council Secretariat, 2006).

\section{Sampling of Rumen Fluid, Blood, and Milk}

The sampling methods and times used were described in a previous study (Miyazawa et al., 2007). Briefly, feed intake was registered for the test period. Rumen fluid was sampled by a suction pump using a stainless catheter (Fujihira Industries Ltd., Tokyo, Japan) on the last day of each period before feeding $(0 \mathrm{~h})$ and at 2 and $5 \mathrm{~h}$ after feeding. Rumen fluid was percolated through 2 layers of gauze, and $\mathrm{pH}$ was measured immediately. One milliliter of fresh rumen fluid was mixed into 4 $\mathrm{mL}$ of methyl green-formalin-saline for the counting of protozoa with the aid of a Fuchs-Rosenthal chamber (VWR International, West Chester, PA; Bayaru et al., 2001). Rumen fluid samples were stored at $-30^{\circ} \mathrm{C}$ for analysis of ammonia-N concentration and VFA composition.

Blood samples were obtained from the jugular vein (with EDTA disodium salt as an anticoagulant) $2 \mathrm{~h}$ after feeding on the last day of each period and then centrifuged at $3,000 \times g$ for 15 min at $4^{\circ} \mathrm{C}$. Plasma samples were stored at $-30^{\circ} \mathrm{C}$ before biochemical analysis.

Milk yield was recorded automatically every day, and data were used from the test period only (the average of $3 \mathrm{~d}$ ). Milk was sampled according to the milk yield of each cow for the last $2 \mathrm{~d}$ of each period. Samples of milk were stored at $-30^{\circ} \mathrm{C}$ before analysis of fatty acid composition. Some milk samples were refrigerated at $4^{\circ} \mathrm{C}$ before the analysis of milk composition. Samples of rumen fluid, blood plasma, and milk were stored at $-80^{\circ} \mathrm{C}$ before analysis of antioxidant activity. 


\section{Chemical Analysis}

Milk composition, consisting of fat, protein, lactose, TS, and SNF, was measured by semiautomatic infrared spectroscopy (Milko-Scan, 133N, Foss Electric, Hillerød, Denmark). The concentration of VFA in rumen fluid and the fatty acid composition of milk were analyzed by gas chromatography as described in a previous report (Miyazawa et al., 2007). In brief, samples for VFA analysis were mixed with $2 \mathrm{~N} \mathrm{H}_{2} \mathrm{SO}_{4}$ containing $12 \%$ metaphosphoric acid, centrifuged at $5,000 \times g$ for $10 \mathrm{~min}$ at $4^{\circ} \mathrm{C}$, and injected into a gas chromatograph (model GC-8A; Shimadzu Co. Ltd., Kyoto, Japan) fitted with a 10\% Shincarbon column (Shinwa Kako Co. Ltd., Kyoto, Japan). Fat from samples used for fatty acid composition analysis was extracted by the RöseGottlieb method (AOAC, 2000). The fatty acid methyl esterification (FAME) of extracted fat was prepared by saponification (Kamegai et al., 2001). The FAME samples were analyzed in a gas chromatograph (model GC-14A; Shimadzu Co. Ltd.) fitted with a flame ionization detector and integrator. The fatty acid standard used was Supelco 37 Component FAME Mix (catalog no.47885-U, Supelco, Bellefonte, PA). The concentration of ammonia-N was determined by a micro diffusion method (Bayaru et al., 2001).

Plasma glutamic oxaloacetic transaminase, total protein, albumin, BUN, total bilirubin, total cholesterol, calcium, and phospholipid concentrations were analyzed by automatic analyzer (Dri-chem4000, Fuji Film, Tokyo, Japan). The concentrations of urea-N, triacylglycerol, NEFA, and glucose in plasma were analyzed by assay kits according to the manufacturer's instructions (Wako Pure Chemical Co., Osaka, Japan).

Antioxidant activities and lipid peroxidation were estimated by 1,1-diphenyl-2-picrylhydrazyl (DPPH) free radical scavenging activity, relative superoxide dismutase (SOD) activity, and thiobarbituric acid reactive substances (TBARS) assay, respectively. The scavenging activities of DPPH and SOD were determined by the method of Li et al. (2009) and Fulghum and Worthington (1984), respectively. The TBARS content was analyzed using a commercially available TBARS assay kit (Cayman Chemical, Ann ARbor, MI) according to the method of Aoki et al. (2008).

\section{Statistical Analysis}

Data were statistically analyzed as a $3 \times 3$ Latin square design using the PROC MIXED procedure of SAS (SAS Version 9.2, SAS Institute Inc., Cary, NC) according to the method described by Hristov et al. (2009). Group and cow within group were random effects, whereas all other factors were fixed. The data of rumen fermentation were calculated by the average of 3 sampling times using the repeat statement. Statistical differences were declared at $P<0.05$. Differences between treatments at $P<0.10$ were considered as a trend toward significance. The significant interactions of treatment versus period (time) were not detected in the present study, and so the $P$-values of the interactions are not shown in the results.

\section{RESULTS}

\section{Feed Intake and Milk Production of Dairy Cows}

The DMI of cows fed a trehalose-supplemented diet was greater than that of cows fed a cellobiosesupplemented diet $(P<0.01)$, whereas there was no difference between the trehalose-supplemented and control-diet-fed groups (Table 2). Milk yields of cows fed trehalose were greater than those of cows fed control or cellobiose-supplemented diets $(P<0.05)$. The milk fat and TS contents of milk from cows fed the trehalose-supplemented or control diets were greater than those in cows fed the cellobiose-supplemented diet $(P<0.05)$. No differences among the diets were found in relation to other milk composition parameters, i.e., lactose and SNF content.

\section{Ammonia-N, VFA, and Protozoal Number in Rumen Fluid}

Table 3 shows differences in ammonia-N and VFA levels and protozoal numbers in the rumen fluid of dairy cows fed a trehalose- or cellobiose-supplemented diet. The ammonia- $\mathrm{N}$ concentration was not changed by trehalose or cellobiose supplementation. Total VFA concentrations in the rumen fluid of dairy cows fed a cellobiose-supplemented diet were greater than those in the control group. Although the acetic acid concentration in the rumen fluid of dairy cows fed a cellobiosesupplemented diet tended to be less than that in control cows $(P=0.07)$, the concentration of propionic acid and isobutyric acid in cows fed a cellobiose-supplemented diet was greater than that in control-diet-fed animals $(P=0.08$ and 0.09 , respectively). The VFA composition of rumen fluid from cows fed a trehalosesupplemented diet was similar to that from cows fed the cellobiose-supplemented diet, whereas total VFA concentrations in the rumen fluid of dairy cows fed a trehalose- supplemented diet tended to be greater than that in the control group $(P=0.08)$. Total protozoa numbers were increased by supplementation of the diet with trehalose or cellobiose compared with the control group. The high number of protozoa in the rumen fluid of dairy cows fed the trehalose- and cellobiose-supple- 
Table 2. Dry matter intake, milk yield, and milk composition of dairy cows fed diets supplemented with $1 \%$ trehalose or $1 \%$ cellobiose $(\mathrm{n}=9)$

\begin{tabular}{lcccc}
\hline Item & Control & Trehalose & Cellobiose & SEM \\
\hline DMI $(\mathrm{kg} / \mathrm{d})$ & $20.6^{\mathrm{b}}$ & $21.2^{\mathrm{a}}$ & $19.8^{\mathrm{b}}$ & 0.6 \\
Milk yield (kg/d) & $20.5^{\mathrm{b}}$ & $21.2^{\mathrm{a}}$ & $20.4^{\mathrm{b}}$ & 1.2 \\
Milk composition (\%) & & & & \\
Protein & 3.6 & 3.6 & 3.6 & 0.0 \\
Fat & $4.7^{\mathrm{a}}$ & $4.8^{\mathrm{a}}$ & $4.5^{\mathrm{b}}$ & 0.1 \\
Lactose & 4.6 & 4.6 & $4.5^{\mathrm{a}}$ & 0.1 \\
SNF & 9.2 & 9.2 & 9.2 & 0.1 \\
TS & $13.9^{\mathrm{a}}$ & $14.0^{\mathrm{a}}$ & $13.7^{\mathrm{b}}$ & 0.2 \\
\hline
\end{tabular}

${ }^{\mathrm{a}, \mathrm{b}}$ Different superscripts within a row indicate significant differences $(P<0.05)$.

mented diets was due to an increase in the number of Entodinium.

\section{Biochemical Composition of the Plasma}

Most parameters of plasma biochemical composition remained unchanged in response to the different dietary treatments. However, the concentration of BUN in the plasma of cows fed a cellobiose-supplemented diet was greater than that in those fed the trehalosesupplemented or control diets (Table 4).

\section{Fatty Acid Composition of Milk Fat}

The concentration of C8:0 and C10:0 fatty acids in the milk of dairy cows fed trehalose- or cellobiose-supplemented diets was less than that in the control group (Table 5). In contrast, concentrations of C18:0 and C18:1 fatty acids were increased in the milk from cows fed a trehalose-supplemented diet compared with the control group. The concentration of $\mathrm{C} 4: 0$ and $\mathrm{C} 18: 3 \mathrm{n}-3$ fatty acids in the milk of dairy cows fed cellobiosesupplemented diets was less than that in the trehalose or control group.

\section{Radical Scavenging Activity, Relative SOD Activity, and Lipid Peroxidation}

The DPPH radical scavenging activities in the rumen fluid of dairy cows fed the trehalose-supplemented diet tended to be greater than those of control cows 2 and 5 $\mathrm{h}$ after feeding and were greater in cellobiose-fed cows 2 and $5 \mathrm{~h}$ after feeding compared with controls (Table 6 ). Radical scavenging activities measured in the plasma and milk of cows fed the trehalose-supplemented diet were greater than those in control cows, whereas those in the plasma and milk of cows receiving the cellobiosesupplemented diet were not different from control values.

Relative SOD activity $2 \mathrm{~h}$ after feeding was greater in the rumen fluid of cows fed trehalose- and cellobiosesupplemented diets compared with the control, and relative SOD activity $5 \mathrm{~h}$ after feeding was greater in those fed a cellobiose-supplemented diet compared with the control (Table 6). There were no differences in the relative SOD activity measured in plasma and milk among any of the dietary treatments.

Lipid peroxidation, estimated as a function of the TBARS content, in the rumen fluid and plasma of cows

Table 3. Ammonia-N, VFA, and protozoal number in rumen fluid of dairy cows fed diets supplemented with $1 \%$ trehalose or $1 \%$ cellobiose $(\mathrm{n}=9)$

\begin{tabular}{lcccc}
\hline Item & Control & Trehalose & Cellobiose & SEM \\
\hline Ammonia-N $(\mathrm{mg} / \mathrm{dL})$ & 12.7 & 12.0 & 11.9 & 0.7 \\
Total VFA $(\mathrm{m} M)$ & $83.3^{\mathrm{b}}$ & $85.2^{\text {ab }}$ & $97.2^{\mathrm{a}}$ & 4.5 \\
VFA composition (molar \%) & & & & \\
Acetic acid & 65.2 & 64.5 & 63.6 & 3.2 \\
Propionic acid & 18.3 & 18.6 & 19.0 & 0.9 \\
Isobutyric acid & 1.2 & 1.2 & 1.6 & 0.1 \\
Butyric acid & 12.2 & 12.5 & 12.4 & 0.6 \\
Isovaleric acid & 1.6 & 1.5 & 1.7 & 0.1 \\
Valeric acid & 1.5 & 1.7 & 1.8 & 0.1 \\
Protozoal numbers $\left(\times 10^{4} / \mathrm{mL}\right)$ & & & $49.4^{\mathrm{a}}$ & 2.4 \\
Total numbers & $42.4^{\mathrm{b}}$ & $48.6^{\mathrm{a}}$ & $46.6^{\mathrm{a}}$ & 2.3 \\
Entodinium & $39.0^{\mathrm{b}}$ & $45.2^{\mathrm{a}}$ & 0.4 & 0.0 \\
Isotricha & 0.8 & 0.8 & 1.3 & 0.1 \\
Dasytricha & 1.2 & 1.4 & 1.3 & 0.1 \\
Others & 1.4 & 1.2 & & \\
\hline
\end{tabular}

${ }^{\mathrm{a}, \mathrm{b}}$ Different superscripts within a row indicate significant differences $(P<0.05)$. 
Table 4. Biochemical composition in plasma of dairy cows fed diets supplemented with $1 \%$ trehalose or $1 \%$ cellobiose $(\mathrm{n}=9)$

\begin{tabular}{|c|c|c|c|c|}
\hline Item $^{1}$ & Control & Trehalose & Cellobiose & SEM \\
\hline Glucose (mg/dL) & 58.9 & 61.7 & 62.1 & 1.4 \\
\hline GOT $(\mathrm{U} / \mathrm{L})$ & 71.5 & 70.9 & 65.7 & 4.7 \\
\hline Total protein $(\mathrm{g} / \mathrm{dL})$ & 7.1 & 7.1 & 7.1 & 0.1 \\
\hline Albumin $(\mathrm{g} / \mathrm{dL})$ & 3.8 & 3.7 & 3.7 & 0.1 \\
\hline BUN (mg/dL) & $17.7^{\mathrm{b}}$ & $16.7^{\mathrm{b}}$ & $19.7^{\mathrm{a}}$ & 0.6 \\
\hline Total bilirubin (mg/dL) & 0.3 & 0.3 & 0.3 & 0.1 \\
\hline Total cholesterol (mg/dL) & 212.0 & 223.0 & 215.2 & 12.7 \\
\hline Caladium (mg/dL) & 9.2 & 9.3 & 9.0 & 0.2 \\
\hline NEFA $(\mathrm{mEq} / \mathrm{L})$ & 0.3 & 0.3 & 0.3 & 0.1 \\
\hline Phospholipid (mg/dL) & 177.7 & 191.4 & 185.9 & 10.0 \\
\hline Triglyceride $(\mathrm{mg} / \mathrm{dL})^{\prime}$ & 9.6 & 9.6 & 9.3 & 0.3 \\
\hline Globulin $(\mathrm{g} / \mathrm{dL})$ & 3.4 & 3.4 & 3.3 & 0.1 \\
\hline Ammonia-N (mg/dL) & 21.5 & 20.7 & 21.6 & 0.4 \\
\hline
\end{tabular}

${ }^{\mathrm{a}, \mathrm{b}}$ Different superscripts within a row indicate significant differences $(P<0.05)$.

${ }^{1} \mathrm{GOT}=$ glutamic oxaloacetic transaminase.

fed trehalose- or cellobiose-supplemented diets was less than that measured in the control-diet-fed group (Table $6)$. Supplementation of the diet with trehalose resulted in lower levels of lipid peroxide in milk compared with those seen for control or cellobiose-supplemented diets.

\section{DISCUSSION}

Many reports have been published that attest to the beneficial effects of increased antioxidant content in foods, such as prevention of disease and aging and improved health. These effects are mediated by the reduced damage caused by ROS (Herrera et al., 2009).
The feeding of high antioxidant diets to farm animals might not only result in higher quality animal products (such as high antioxidant and low lipid peroxide containing products), but also provide health benefits for people who consume these products (Mukhtar and Ahmad, 2000). Milk with high antioxidant and low lipid peroxide content had not been developed until now, despite previous attempts to reduce oxidative damage by supplementing the diets of dairy cows with vitamin E, a commonly used natural antioxidant (Bouwstra et al., 2008). In this manner, we evaluated the effect of supplementation of the diet with trehalose, a natural disaccharide with antioxidant activity, on oxidative

Table 5. Fatty acid composition in milk fat (mg/100 mg of fatty acid methyl esterification) of dairy cows fed diets cows supplemented with $1 \%$ trehalose or $1 \%$ cellobiose $(n=9)$

\begin{tabular}{lcccc}
\hline Fatty acid $^{1}$ & Control & Trehalose & Cellobiose & SEM \\
\hline C4:0 & $1.61^{\mathrm{a}}$ & $1.51^{\mathrm{ab}}$ & $1.36^{\mathrm{b}}$ & 0.07 \\
C6:0 & 1.76 & 1.68 & 1.68 & 0.04 \\
C8:0 & $1.28^{\mathrm{a}}$ & $1.20^{\mathrm{b}}$ & $1.20^{\mathrm{b}}$ & 0.02 \\
C10:0 & $3.20^{\mathrm{a}}$ & $2.93^{\mathrm{b}}$ & $2.93^{\mathrm{b}}$ & 0.16 \\
C12:0 & 3.86 & 3.70 & 3.71 & 0.20 \\
C14:0 & 13.13 & 12.68 & 12.70 & 0.35 \\
C14: 1 & 1.16 & 1.14 & 1.20 & 0.05 \\
C16:0 & 36.60 & 35.42 & 36.62 & 0.81 \\
C16:1 & 1.74 & 1.72 & 1.87 & 0.11 \\
C18:0 & $9.75^{\mathrm{b}}$ & $10.71^{\mathrm{a}}$ & $10.19^{\mathrm{ab}}$ & 0.41 \\
C18:1 & $22.38^{\mathrm{b}}$ & $23.85^{\mathrm{a}}$ & $23.28^{\mathrm{ab}}$ & 1.11 \\
trans-11 C18:1 & 0.07 & 0.05 & 0.03 & 0.04 \\
C18:2 & 1.98 & 2.00 & 1.91 & 0.25 \\
CLA & 0.54 & 0.58 & 0.56 & 0.04 \\
C18:3n-3 & $0.38^{\mathrm{a}}$ & $0.31^{\mathrm{ab}}$ & $0.27^{\mathrm{b}}$ & 0.04 \\
C18:3n-6 & 0.15 & 0.14 & 0.13 & 0.02 \\
C20:0 & 0.12 & 0.11 & 0.11 & 0.02 \\
C20:4n-6 & 0.15 & 0.14 & 0.14 & 0.03 \\
C20:5n-3 & 0.05 & 0.05 & 0.04 & 0.02 \\
C22:6n-3 & 0.04 & 0.04 & 0.04 & 0.01 \\
PUFA & 3.44 & 3.41 & 3.24 & 0.13 \\
\hline
\end{tabular}

${ }^{\mathrm{a}, \mathrm{b}}$ Different superscripts within a column indicate significant differences $(P<0.05)$.

${ }^{1} \mathrm{CLA}=$ conjugated linoleic acid; PUFA $=$ polyunsaturated fatty acid. 
Table 6. The 1,1-diphenyl-2-picrylhydrazyl (DPPH) radical scavenging activity, superoxide dismutase (SOD) activity, and thiobarbituric acid reactive substances (TBARS) in rumen fluid, milk, and plasma or blood of dairy cows fed diets supplemented with $1 \%$ trehalose or $1 \%$ cellobiose $(\mathrm{n}=9)$

\begin{tabular}{|c|c|c|c|c|c|}
\hline Item & $\begin{array}{l}\text { Time after } \\
\text { feeding }(\mathrm{h})\end{array}$ & Control & Trehalose & Cellobiose & SEM \\
\hline \multicolumn{6}{|l|}{$\mathrm{DPPH}(\mathrm{U} / \mathrm{mL})$} \\
\hline \multirow[t]{3}{*}{ Rumen fluid } & 0 & 188.9 & 153.3 & 165.0 & 20.4 \\
\hline & 2 & $303.7^{\mathrm{b}}$ & $346.7^{\mathrm{ab}}$ & $429.9^{\mathrm{a}}$ & 30.9 \\
\hline & 5 & $219.9^{\mathrm{b}}$ & $262.1^{\mathrm{ab}}$ & $356.7^{\mathrm{a}}$ & 29.9 \\
\hline Plasma & 2 & $126.3^{\mathrm{b}}$ & $202.2^{\mathrm{a}}$ & $154.4^{\mathrm{b}}$ & 11.3 \\
\hline Milk & - & $85.3^{\mathrm{b}}$ & $116.8^{\mathrm{a}}$ & $107.3^{\mathrm{ab}}$ & 4.5 \\
\hline \multicolumn{6}{|c|}{ Relative SOD activity (\% of inhibition) } \\
\hline \multirow[t]{3}{*}{ Rumen fluid } & 0 & 21.0 & 22.8 & 23.3 & 1.3 \\
\hline & 2 & $21.4^{\mathrm{b}}$ & $29.9^{\mathrm{a}}$ & $29.4^{\mathrm{a}}$ & 1.4 \\
\hline & 5 & $26.1^{\mathrm{b}}$ & $25.2^{\mathrm{b}}$ & $33.3^{\mathrm{a}}$ & 1.4 \\
\hline Blood & 2 & 28.2 & 27.1 & 26.1 & 1.6 \\
\hline Milk & - & 21.0 & 21.4 & 21.1 & 0.1 \\
\hline \multicolumn{6}{|c|}{ TBARS ( $\mu M$ malondialdehyde) } \\
\hline \multirow[t]{3}{*}{ Rumen fluid } & 0 & 3.4 & 3.2 & 3.0 & 0.4 \\
\hline & 2 & $4.5^{\mathrm{a}}$ & $2.9^{\mathrm{b}}$ & $2.7^{\mathrm{b}}$ & 0.3 \\
\hline & 5 & 3.9 & 2.6 & 3.4 & 0.3 \\
\hline Plasma & 2 & $4.1^{\mathrm{a}}$ & $2.6^{\mathrm{b}}$ & $2.7^{\mathrm{b}}$ & 0.3 \\
\hline Milk & - & $4.6^{\mathrm{a}}$ & $2.6^{\mathrm{b}}$ & $5.1^{\mathrm{a}}$ & 0.4 \\
\hline
\end{tabular}

${ }^{\mathrm{a}, \mathrm{b}}$ Different superscripts within a column indicate significant differences $(P<0.05)$.

status of milk. In the present study, oxidative status was estimated by lipid peroxidation as a function of the TBARS content and antioxidant activity as DPPH radical scavenging and SOD activities. The present results show that supplementation with trehalose in the diet could reduce evidence of oxidative stress in rumen fluid, blood, and milk of dairy cows and thus improve milk quality (Table 6). Furthermore, the supplementation with trehalose resulted in increased milk production and DMI (Table 2). Trehalose could, therefore, be a useful supplement for reducing oxidative stress and providing higher quality milk for human consumption, because supplementation of the diet of dairy cows with trehalose might have the added benefit of reducing or even eliminating lipid oxidative odor.

To provide evidence of a possible mechanism underlying the antioxidant activity associated with trehalose supplementation of the diet, the biochemical composition of plasma, and the VFA content and protozoa number in rumen fluid, were examined in the present study. Results were similar for cows fed diets supplemented with trehalose or cellobiose (Tables 3, 4, and 5). Although the total VFA contents in cows fed diets supplemented with trehalose were not different from those in the control group, the total protozoa numbers in the rumen fluid of dairy cows fed trehalose- or cellobiosesupplemented diets were greater than those of the control group. Superoxide dismutase activity has been detected in ruminal bacteria (Fulghum and Worthington, 1984), and DPPH radical scavenging activity showed a positive correlation with protozoa number in rumen fluid (Gazi et al., 2007). As such, the low lipid peroxide and high antioxidant content in the rumen fluid of cows fed trehalose- or cellobiose-supplemented diets might be, in part, explained by the enhancement of protozoa activities through the activation of fermentation in the rumen fluid. However, the reduction of oxidative stress, i.e., a decrease of TBARS and an increase of DPPH radical scavenger activities, was not seen in milk from cows receiving a cellobiose-supplemented diet, whereas a decrease of TBARS and an increase of DPPH radical scavenger activities were measured in the milk of cows that received the trehalose-supplemented diet compared with that seen in control cows (Table 6).

The lipid oxidation in milk was involved in C18:3n-3 fatty acid contents (Havemose et al., 2006). In the present study, the concentration of C18:3n-3 fatty acid in the milk of cows receiving a trehalose-supplemented diet was not different from that of the control group, whereas the concentration of C18:3n-3 fatty acids in the milk of dairy cows fed cellobiose-supplemented diets was less than that in the trehalose or control group (Table 5). The biochemical parameters measured in plasma from cows fed a diet supplemented with trehalose were similar to those for the cellobiose and control group, except for the BUN concentration in plasma (Table 4). Then, the marked metabolic changes were not induced by the supplementation of trehalose in diets. It is, therefore, likely that the mechanism underlying the increased antioxidant levels in milk in response to trehalose supplementation cannot be explained only by changes in the plasma and milk biochemical compositions. Although an explanation was not forthcoming in the present study as to why different results were 
obtained for milk from cows receiving cellobiose- and trehalose-supplemented diets, it could be that trehalose has a direct or indirect action on milk-producing epithelial cells in the mammary glands. Study of digestion and absorption of trehalose in ruminants and the study of responses to other antioxidant factors may help to elucidate the mechanism whereby the antioxidant activity in the milk of dairy cows is upregulated by dietary supplementation with trehalose.

\section{CONCLUSIONS}

The disaccharides used in this study decreased oxidative stress parameters, such as DPPH radical scavenging activities and contents in the rumen fluid and blood of dairy cows. In addition, trehalose supplementation in the diets of dairy cows produced milk with low lipid peroxide and high antioxidant content, suggesting that trehalose could be useful as a supplement for inhibiting oxidative stress, enabling the production of low-lipidperoxide and high-antioxidant milk for human consumption and decreasing the unwanted effects of lipid oxidative odor in cow's milk.

\section{ACKNOWLEDGMENTS}

The authors thank R. Noma, S. Kobayashi, and M. Aida (Field Science Center, Tokyo University of Agriculture and Technology, Tokyo, Japan) for their technical help.

\section{REFERENCES}

Agriculture, Forestry and Fisheries Research Council Secretariat. 2006. Standard Tables of Feed Composition in Japan. Japan Livestock Industry Association, Tokyo, Japan.

Al-Mabruk, R. M., N. F. Beck, and R. J. Dewhurst. 2004. Effects of silage species and supplemental vitamin $\mathrm{E}$ on the oxidative stability of milk. J. Dairy Sci. 87:406-412.

Aoki, M., T. Oshita, and M. Sakaguchi. 2008. The comparison of thiobarbituric acid reactive substances (TBARS) concentrations in plasma and serum from dairy cattle. J. Vet. Med. Sci. 70:107110 .

AOAC. 2000. Official Method of Analysis of AOAC International, 17th ed. AOAC International, Gaithersburg, MD.

Bayaru, E., S. Kanda, T. Kamada, H. Itabashi, S. Andoh, T. Nishida, M. Ishida, T. Itoh, K. Nagara, and Y. Isobe. 2001. Effect of fumaric acid on methane production, rumen fermentation and digestibility of cattle fed roughage alone. Anim. Sci. J. 72:139-146.

Boots, A. W., G. R. Haenen, and A. Bast. 2008. Health effects of quercetin: From antioxidant to nutraceutical. Eur. J. Pharmacol. 585:325-337.

Bouwstra, R. J., R. M. Goselink, P. Dobbelaar, M. Nielen, J. R. Newbold, and T. van Werven. 2008. The relationship between oxidative damage and vitamin E concentration in blood, milk, and liver tissue from vitamin E supplemented and nonsupplemented periparturient heifers. J. Dairy Sci. 91:977-987.

Fulghum, R. S., and J. M. Worthington. 1984. Superoxide dismutase in ruminal bacteria. Appl. Environ. Microbiol. 48:675-677.

Gazi, M. R., M. Yokota, Y. Tanaka, S. Kanda, and H. Itabashi. 2007. Effects of protozoa on the antioxidant activity in the ruminal fluid and blood plasma of cattle. Anim. Sci. J. 78:34-40.

Havemose, M. S., M. R. Weisbjerg, W. L. Bredie, H. D. Poulsen, and J. H. Nielsen. 2006. Oxidative stability of milk influenced by fatty acids, antioxidants, and copper derived from feed. J. Dairy Sci. 89:1970-1980.

Herrera, E., R. Jiménez, O. I. Aruoma, S. Hercberg, I. Sánchez-García, and C. Fraga. 2009. Aspects of antioxidant foods and supplements in health and disease. Nutr. Rev. 67:S140-S144.

Hristov, A. N., M. Vander Pol, M. Agle, S. Zaman, C. Schneider, P. Ndegwa, V. K. Vaddella, K. Johnson, K. J. Shingfield, and S. K. R. Karnati. 2009. Effect of lauric acid and coconut oil on ruminal fermentation, digestion, ammonia losses from manure, and milk fatty acid composition in lactating cows. J. Dairy Sci. 92:55615582 .

Kamegai, T., M. Kasai, and I. Ikeda. 2001. Improved method for preparation of the methyl ester of conjugated linoleic acid. J. Oleo Sci. 50:237-241.

Li, W., F. S. Hosseinian, A. Tsopmo, J. K. Friel, and T. Beta. 2009. Evaluation of antioxidant capacity and aroma quality of breast milk. Nutrition 25:105-114.

Lindmark-Månsson, H., and B. Akesson. 2000. Antioxidative factors in milk. Br. J. Nutr. 84:S103-S110.

Miyazawa, K., H. Sultana, T. Hirata, S. Kanda, and H. Itabashi. 2007. Effect of brewer's grain on rumen fermentation, milk production and milk composition in lactating dairy cow. Anim. Sci. J. $78: 519-526$.

Mukhtar, H., and N. Ahmad. 2000. Tea polyphenols: Prevention of cancer and optimizing health. Am. J. Clin. Nutr. 71:1698S$1702 \mathrm{~S}$.

Oku, K., M. Kurose, M. Kubota, S. Fukuda, M. Kurimoto, Y. Tujisaka, A. Okabe, and M. Sakurai. 2005. Combined NMR and quantum chemical studies on the interaction between trehalose and dienes relevant to the antioxidant function of trehalose. J. Phys. Chem. B 109:3032-3040.

Oku, K., H. Watanabe, M. Kubota, S. Fukuda, M. Kurimoto, Y. Tsujisaka, M. Komori, Y. Inoue, and M. Sakurai. 2003. NMR and quantum chemical study on the $\mathrm{OH} . . . \mathrm{pi}$ and $\mathrm{CH} . . \mathrm{O}$ interactions between trehalose and unsaturated fatty acids: Implication for the mechanism of antioxidant function of trehalose. J. Am. Chem. Soc. 125:12739-12748.

Sympoura, F., A. Cornu, P. Tournayre, T. Massouras, J. L. Berdagué, and B. Martin. 2009. Odor compounds in cheese made from the milk of cows supplemented with extruded linseed and alphatocopherol. J. Dairy Sci. 92:3040-3048. 